$$
\begin{gathered}
\text { 담낭결석에 대한 담낭초음파도와 경구담낭조영술 } \\
\text { 이화여자대학교의과대학 내과학교실 } \\
\text { 이 승 섭·경 난 호 }
\end{gathered}
$$

$=$ Abstract $=$

\title{
Ultrasonic and Radiographic Cholecystography
}

\author{
Seong Sup Lee, M.D., Nan Ho Kyung, M.D. \\ Department of Internal Medicine, College of Medicine, Ewha Womans University
}

\begin{abstract}
The authors analyzed 34 patients admitted to Ewha Womans University Hospital from January, 1, 1979 to June, 30, 1979 by animpression of cholelithiasis clinically. Ultrasonic and radiologic cholecystography were performed in all patients. In 20 patients of 34 patients, exploration was done. The'result were as follow:

1) The accuracy of gallstone detected by ultrasound was $90 \%$, which confirmed by exploratory laparotomy (20 cases), but $88 \%$ in non-visualized gallbladder by oral cholecystography (20 cases). False positive was $6 \%$ ( 1 case) and false negative was $6 \%$ (1 case).
\end{abstract}

2) In 13 cases (38\%) GB stone was visualized by oral cholecystography, while in 20 cases $(59 \%)$ were nonvisualized GB. Well opacified gall bladder without stone was in 1 case $(3 \%)$.

3) In 20 cases that gall bladder wasn't visualized by oral cholecystography, gall stone was detected in 17 cases (85\%), normal GB in 2 cases (10\%), no stone in 1 case $(5 \%)$ by ultrasonography.

4) Among 20 cases which were confirmed by operation, 4 cases were concomitant with cholecystography, ultrasonography and operative findings. Among 16 cases nonvisualized by oral cholecystography, 15 cases were detected as gall stone by ultrasonography, which were gall stone in 14 cases, normal gall bladder in 1 case (i,e. false positive, $6 \%$ ) and no stone in 1 case (i. e. false negative, 6\%).

\section{서 론}

최근 3 4년 간 급격히 발달한 초음파 검 사의 복부내 장기에 대한 임상적 응용에 따라 담도계질한, 특히 담 낭결석의 진단적 가치에 대해 많은 검토가 진행되고 있 다. 이제까지 경구담낭조영술은 담낭결석의 진단에 비 교적 높은 정확도로 중요한 부분을 담당해왔으나 ${ }^{122}$, 조영체에 과딘체질인 환자, 임 신부등에서 시행하기 어
렵고, 각종 닫낭질환, 담관폐쇄, 담남이외 질환으로 담 낭이 조영되지 않을 경우에는 진단이 어려우므로, 이들 경우 비침입적인 방법으로 부담없이 시행할 수 있는 초 음파검사가 각광을 받고 있다 ${ }^{34}$.

\section{관찰대상 및 방법}

저자는 1979년 1월부터 1979년 6월 까지 6개월간 이 화대학병원 네과에 입원하였던 환자중 임상적으로 담 
낭결석이 의심된 환자 34 예에 대해 경구담낭 조영술과 초음파검사를 시행하고, 이중 20 예에서 수술하여 다음 과 같은 결과를 얻었기에 보고하는 바이다.

사용된 기구는 일본 Hitachi사의 Compound B scan 인 EUB-3형과 Real time scan인 EUB-21형이었고, 사용된 탐측자의 음파는 2.5 와 $3.5 \mathrm{MHz}$ 및 $3.0 \mathrm{MHz}$,

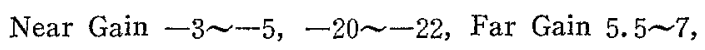
$4 \sim 5.4$, T.G.C. $1.0 \sim 1.5 \mathrm{~dB} / \mathrm{cm}$ 를 환자의 Depth에 따 라 조절하여 사용하였고, Scale factor는 (EUB-3형) 1 division을 $2 \mathrm{~cm}$ 로 고정하여 사용하였다.

초음퐈점사방법은 환자를 12 시간 절식시킨 후, 우상 복부에 olive oil을 발라서 탐측자를 푀부여 밀착시커 공기충이 없도록 하고, supine position에서 transverse, longitudinal, oblique로 주사하였고, 필요에 따 라 left decubitus position에서 right anterior oblique 로 주사하였다.

\section{결 과}

경 구담낭조영술을 시행한 34 예 중 조영되지 않은 예 는 20예, 담낭결석 13예, 정상담낭 1예였고, 초음마검 사 결과 담낭결석 31 예, 담낭을 발견할 수 없었든 경우 1예, 정상담낭 2예였다(표 1).

초음파검사로 담낭을 발견할 수 없였던 1예의 겅상 담낭 2예는 경구담낭조영술로 조영되지 않았던 예들이 다.

초음파검사로 진단된 담낭결석 31 예는 경 구담낭조영 술로 담낭결석 13예, 비조영담낭 17예, 정상담낭 1예 였다.

34예중 20예는 수술하였으며 그 결과 담낭결석 19예 이상소견을 발견할 수 없었던 예는 1예였다(표 2).

수술하여 담남결석으로 확진된 환자중 4예는 경 구담 낭조영술과 초음화검사로 담낭결셕이었던 예이며 14예 는 경 구담낭조영술로 조영되지 않았으나, 초읍파감사

Table 1. Comparison of cholecystography and ultrasonography in 34 patients

\begin{tabular}{lcrrrr}
\hline \hline & \multicolumn{2}{c}{$\begin{array}{c}\text { Oral cholecystography } \\
\text { No. of cases }\end{array}$} & \multicolumn{2}{c}{$\begin{array}{c}\text { Ultrasonography } \\
\text { No. of cases } \%\end{array}$} \\
\hline Non-visualization & 20 & 59 & 1 & 3 \\
GB stone & 13 & 38 & 31 & 91 \\
Normal GB & 1 & 3 & 2 & 6 \\
\hline Total & 34 & 100 & 34 & 100 \\
\hline
\end{tabular}

*GB: Gall bladder.

Table 2. Oral cholecystography and ultrasonographic findings in surgically confirmed 20 patients

\begin{tabular}{llccc}
\hline & & \multicolumn{2}{c}{ Ultrasonography } & Total \\
& & Stone & Normal & \\
\hline \multirow{2}{*}{ Oral cholecystography } & GB stone & 4 & - & 4 \\
& Non-visualization & $15^{*}$ & $1^{* *}$ & 16 \\
\hline & Total & 19 & 1 & 20 \\
\hline
\end{tabular}

* 1 among 15 patients was confirmed as normal GB after surgery (false positive)

** Ultrasonographic normal GB was confirmed as GB stone after surgery (false negative)

Table 3. Comparison of ultrasound results in 20 patients with non-visualization following oral cholecystography

\begin{tabular}{lcccc}
\hline & Normal & $\begin{array}{c}\text { Ultrasonography } \\
\text { Stones }\end{array}$ & Non-visualization & Total \\
\hline Oral non-visualization & 2 & 17 & 1 & 20 \\
No. of surgery cases & 1 & 15 & - & 16 \\
Cases of calculi & 1 & 14 & - & 15 \\
\hline
\end{tabular}


로 담석증이 진단되었던 예였고, 1 예는 경구담낭조영 술로 조영되지 않았으나 초음파검사로 정상담낭을 보 인 예었다.

이상소견을 발견할 수 없었던 1예는 경 구담낭조영술 로는 조엉되지 않았으나 초음퐈검사로 담석중이 진단 된 예였다.

경구담낭조영술로 조영되지 않았던 20예에 대한 초 음퐈검사는 정상담낭 2예, 담낭졀석 17예, 담낭을 발 견할 수 없었던 예가 1예였다. 이중 수술로 남낭결석 이 확인된 15예는 초음파검사로 담낭결석을 보인 14예 와 정상담낭소견을 보인 1예였고, 수슬결과 이상소견 을 발견할 수 없었던 1예는 초음퐈검사로 담낭결석을 보인 예였다 (표 3 ).

\section{고 안}

담낭에 초음파.진단이 척음 시도된 것은 1950년경 부 터 Ballentine, 菻地喜充, 田中憲二, 和賀井敏夫, Ludwig, Howry, Wild등에 의해서였으나, 1970년대로 들 어오면서 복부내 장기에 대한 초음퐈의 활발한 응용과 더불어 담낭결석에도 초음파검사가 활발하여 졌닿․

초음파촬영술에 의한 담낭결석 진단의 정확도는 김 사자의 능숙도에 따라 다르고 ${ }^{3}$, 담낭결석으로 진단된 환자라도 실졔 개복하여 확진되는 경우는 제 한되어 있 으므로 현 실정에서 이에 대하여 확실한 정확도를 말 하기는 어려우나 이계까지 보고된 정확도는 Doust ${ }^{4)}$ 80\%, Goldberg ${ }^{6 /} 72 \%$, Leopold 73 91\%, Arnon ${ }^{31}$ 90\%, Royal $^{83} 93 \%$, Crade $^{92} 96 \%$ 로 해마다 증가하는 추세 에 있다.

초음파촬영술의 기술적 어려움과 담낭의 발견이 힘 든 경우는 장내 gas가 많은 경우, 비만형, 담낭이 늑 골에 의하여 흉곽내 높이 횡행으로 위치한 경우, 수술 반흔, 담석이 담낭에 작 차 있을 때와 아주 작은 담낭 등이 다 ${ }^{6) 10111)}$.

본 연구에서는 초읍파검사 결놔 담석증에 대한 정확 도는 수술한 20데에 대해 $90 \%$ 로 Goldberg ${ }^{7}$ 의 $72 \%$ 에] 비해 더 늪은 정확도를 보였으나, Doust ${ }^{6)}, \mathrm{Arnon}^{3}$ 의 $80 \%, 90 \%$ 등과는 비슷하고, Leopold ${ }^{88}$, Royal ${ }^{9}$, $\mathrm{Crade}^{102}$ 등의 $91 \%, 93 \%, 96 \%$ 보다는 낮은 비 율이지 만 아직 우리나라에서 초음파검사가 초기단계에 있다 는 점을 감안해야 할 것같다.

경구담낭조영술로 조영되지 않은 20 예에 태한 초음 파검사의 정확도.는 $88 \%$ 로 담낭걸석 17 예 (85\%), 정상 담낭 2 예 ( $10 \%)$, 담낭이 보이지 않는 경우가 1예 (5\%) 였으며, 이중 16예에서 시험개복하여 15예에서 담낭결
석이 확진되였으며 그의 위양성 1 예(6\%), 위음성 1 예 (6\%)였다.

경구담낭조영술로 조영되지 않은 예에 대한 초음파 검사의 정확도는 Goldberg's)의 $68 \%$ 에 비해 본 연 7 에 서는 $88 \%$ 로 높았고, Goldberg'긱의 위양성 $12 \%$, 위음 성 $75 \%$ 는 본 연구의 위양성과 위음성 각 $6 \%$ 에 비해 현저히 높은 비율을 나타내고 있다.

일반적으로 담낭결석을 진단함에 있어서 경구담낭조 영술이 초음파검사예 비해 아직까지는 우월한 것으르 보고되어, Goldberg ${ }^{6)}$ 는 초음파진단 $72 \%$ 에 비해 경구 닫낭조영술의 정확도가 $85 \%$ 로 우월하다고 하었고, Royal'8) 역시 경구담낭조영술이 우월하다고 하였으나 본 연구의 초음파진단 $90 \%$ 의 정확도에 대한 경 구답낭 조영술의 정확도는 경구담낭조영술로 진단된 담낭결석 은 4예에서만 수술이 시행되였으며 그 결과 4 예 모두 에서 결석이 발견되어 그 정확도는 100\%라 하갰으나 그 예수가 적으므로 이것만으로는 그 점확도를 평가하 기는 어렵다고 보겠다.

이상으로 미루어 보아 경구담낭조영술결과 담낭결석 으로 나타난 에에 대하여서는 초음파검사와 볘교하여

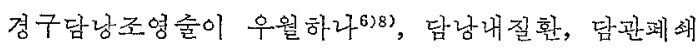
담낭외질환 등으로 경 구담낭조영술로 담낭이 조영되지 않은 경우와 조영게에 과민한 체질, 임신부에 대해서 는 초음파검사가 경구담낭조영술에 비해 유용한 진단 방법이 될 것으로 사료된다.

\section{결 론}

1979년 1월부터 1979년 6월까지 6개월간 이화대학병 원 내과에 입원하였던 환자중 임상적으로 담낭결석이 의심되었던 환자 34 예에 대하여 겸 구담낭조영술과 초 음파김사를 시행하였고 이중 20예에서 시혐개복하여 다 음과 같은 결론을 덛었다.

1) 초음파의 담남결석에 대 한 정확도는 수술한 20예에 대해 $90 \%$, 경구담낭조영술로 조영되지 않은 20에에 대 해서는 $88 \%$ 였으며 위양성 1예(6\%), 위음성 1예(6\%) 였다.

2) 담낭결석에 대한 경구담낭조영술로 담석이 나타 난 예는 34예중 13예로 $38 \%$, 조영되지 않은 예는 20 예로 $59 \%$, 담낭은 조영되었으나 담석이 없는 경우는 1 예로 $3 \%$ 였다.

3) 경구담낭조영술로 담낭이 조영되지 않은 환자 20 예중 초음파로 담낭결석이 받견된 예는 17 뎨 $(85 \%)$, 정 상담낭 2예 (10\%), 담낭을 발견할 수 없 었던 경우가 1예 (5\%)였다. 
4) 수술로 확진된 20예충 4예는 경 구담낭조영 술과 초 음퐈진단, 수술소견이 일치하였던 예이고, 경구닪낭조 영출로 조영되지 않은 16예에서 초음파진단 결과 담낭 결석이 있었던 15예는 14예에서 결석이 있었고 1예는 정상담낭을 보여 위양성 $6 \%$, 나머지 1 예는 수술결과 결석을 발견할 수 없어 위음성은 $6 \%$ 였다.

\section{-References-}

1) Baker, H.L. and Hodgson, J.R.: Further studies on the accuracy of oral cholecystography, $\mathrm{Ra}$ diology, $74: 239,1960$.

2) Ochsner, S.F.: Performance and reliability of cholecystography, South Med. J., 63: 1268, 1970.

3) Arnon, S. and Rosenquist, C.J.: An evaluation of accuracy, Am. J. Roentgenol, 127:817, 1976.

4) Doust, B.D. and Maklad, N.F.: Ultrasonic BMode examination of the gall bladder, Radio$\log \mathrm{y}, 110: 643.1974$.

5）井田吉搏，大竹昭，遠田榮一，林璸，古木量一的：
超音波檢查技術入門，超音波醫學檢查技術破究會， 日本, 1976 .

6) Goldberg, B.B., Harris, K., Brooker, W.: Ultrasonic and radiographic cholecystography, Radiology, $111: 405,1974$.

7) Leopold, G.R., Sokoloff, J.: Ultrasonic scanning in the diagnosis of billiary disease, Surg. Clin. N. Am., $53: 1043,1973$.

8) Royal, J., Bartrum, J.R., Harte, C.C. and Shelia, R.F.: Ultrasonic and radiographic cholecystography, New Engl. J. Med., $296:$ 538, 1977.

9) Crade, M., Taylor, K.J.W., Rosenfield, A.T., Graaff, C.S. and Minihan, P.: Surgical and pathologic correlation of cholecystosonography and cholecystography, Am. J. Roentgenol. 131 : 227,1978 .

10) Malini, S. and Sabel, J.: Ultrasonography in obstructive jaundice, Radiology, $123: 429,1977$.

11) Hublitz, U.F., Kahn, P.C. and Sell, L.A.: Cholecystosonography: An approach to the nonvisualized gall bladder, Radiology, 103:645, 1972.

\section{Explanation of Figures}

Oblique scan, right upper quadrant at the bottom of the gall bladder, a layer of tiny stones is seen which results in a broad acoustic shadow(S).

Fig. 1. by compound B-scan.

Fig. 2. by real-time electronic scan.

Fig. 3. Longitudinal scan, right upper quadrant, showes a calculus which casts an acoustic shadow(S).

Fig. 4. Cholecystosonogram, longitudinal section, An enlarged gall bladder is seen in a patient with chronic inflamation and gall stones. (arrow: sludge) 
$\square$ 이 승섭 외 논문 사진부도 $\square$

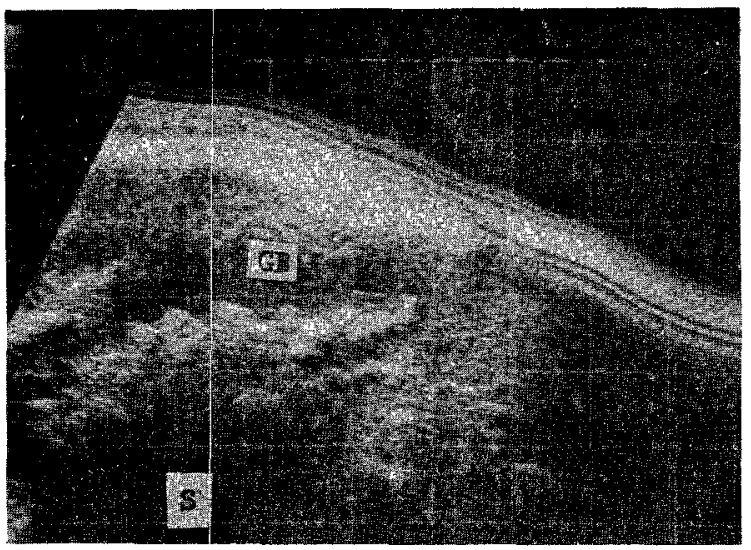

Fig. 1.

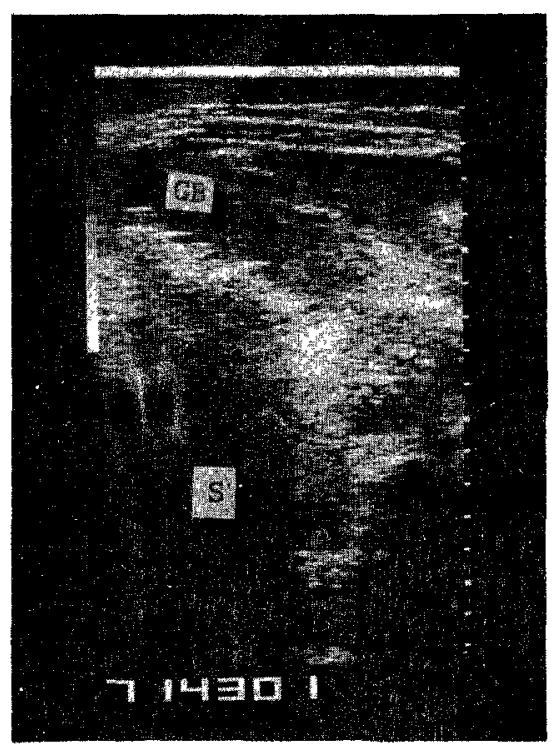

Fig. 2.

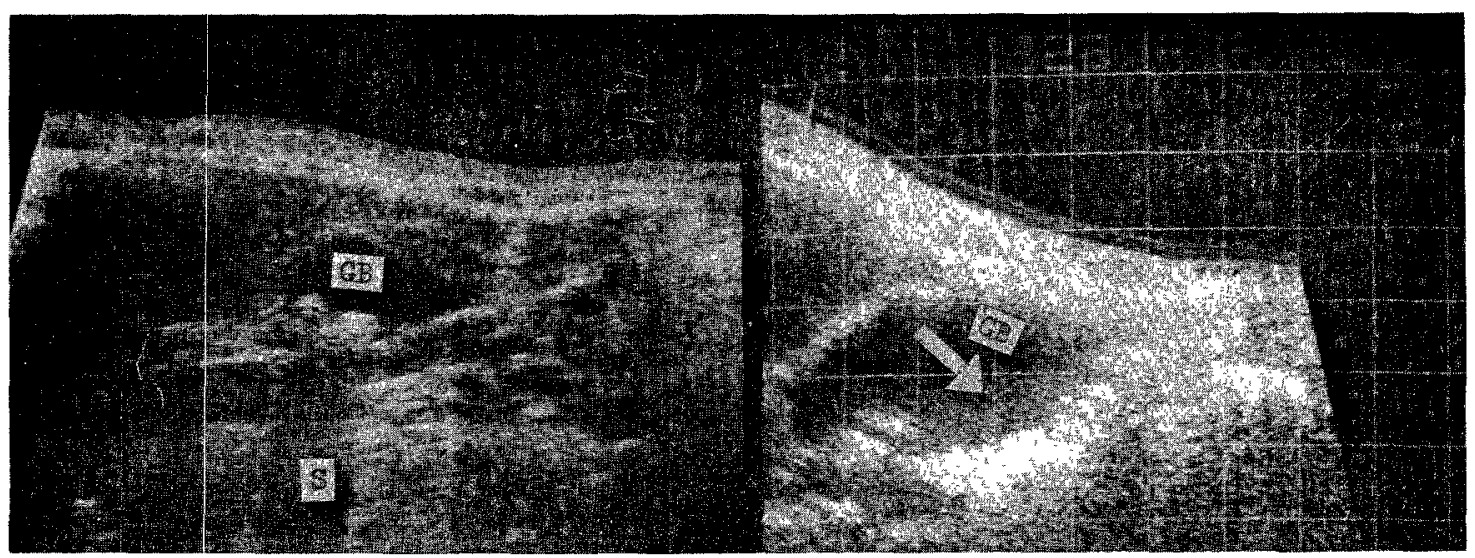

Fig. 3.

Fig. 4. 